\title{
The Translator's Art of Failure: Engaging the Other in Imperfect Harmony ${ }^{1}$
}

Katherine Silver,

Translator

I was fortunate, in a skewed kind of way, to get a rather stark insight into one aspect of the translator's so-called worldview, namely my own, when I saw my name on the website dedicated to "The Translator as Theorist?" conference accompanied by that one little word "translator." What better place to start, I thought, than with my own attitude toward myself and my work. My first impulse was to write to my generous hosts and ask them to add a few more little words-something like editor, writer, teacher. It seems I was feeling inadequate as "only" a translator to talk about translating on International Translation Day. The fact is, I am not "only" a translator, most of us aren't, this in large part because of the brutal, prosaic fact that it is practically impossible to make a living in the United States today-and I suspect in Canada as well-by working exclusively as a translator, let alone a literary translator. And, in keeping with my belief that it is imperative for a translator to be conscious of and able to articulate her underlying, unspoken assumptions and those of her culture and other cultures, I notice what I would call a dialectical relationship between the "objective material conditions" and my momentary sense of inadequacy. Apart from all the other theoretical considerations that swirl around literary translation, I begin to wonder if the texts we produce are deemed subordinate to the original in part because our practice itself must be subordinate to a day job. Maybe it's these objective material conditions themselves that make the very term "professional literary translator" something of an oxymoron. Would a radical shift in our class status, our relationship to the means of production, would earning a living wage give us, and our products, a more clearly defined place?

I know. This is a rather prosaic, mundane way to look at things. But a place seems to be what we translators, and translation in general, lack. Translation is, so to speak, neither here nor there. Between languages, between cultures, neither in full view

\footnotetext{
${ }^{1}$ An earlier version of this paper was presented as the keynote address at the Sixth International Translation Day Conference at the University of Alberta (Edmonton, September 30, 2008). I would like to thank my hosts, Anne Malena and Lynn Penrod, for inviting me there and giving me this opportunity to formulate and share my thoughts about translating. We met in 2007 at the Banff International Literary Translation Centre, where I spent three life-changing weeks. I was quite moved to be back in Alberta just a little over a year later.
}

(C) Copyrights TransculturAl \& Author (2009) 
nor invisible. When I first started thinking and reading in preparation for this talk, I noticed that translators are often described as being caught in the clutches of a series of paradoxes that get translated into dilemmas through our work. Translations are Les belles infidèles, an expression I first heard in translation, or interpretation, in Spanish as "translations are like women, either beautiful or faithful." We, women and translators, are true either to the letter, sometimes thought of as the body, or the spirit. The language we reproduce on the page is either too fluent, familiar, complacent, or too literal. Translating is often characterized as a high-wire act over a pit of snakes called aesthetic and ethical compromise, textual betrayal, the limitations of language itself, the failure to find equivalencies. We are told that nothing that truly matters-mystery, poetry, resonance, the ineffable-can really be translated; it can only be re-created in a new language, as if those two activities-translating and re-creating-were not ultimately the same thing anyway. And yet, we carry on, day in and day out, losing, missing, betraying, mangling, falling short. Failing?

There is no question that the practice of literary translation is a constant reminder of the plurality of meaning, even, dare I say, truth, and of the importance of context for that meaning. Translators must find some kind of satisfaction in relative equivalencies and imperfect solutions, or quit. But I have come to recognize that my actual experience during the practice itself - which always assumes, if we look deeply enough, an implicit theory -is not primarily one of conflict, self-denial, or subordination, and that there is, in fact, a "place" I inhabit with increasing comfort and ease. This is especially true since I returned to translating about seven years ago after an almost ten-year hiatus, a hiatus due, I always thought, to the meta-material condition I found myself in of raising children and having to earn a living. The odd thing is, I attribute my return to translating in large part to having fallen in love.

\section{II}

You might ask, as the song does, what's love got to do with it? I'm not sure, maybe because I'm not sure yet what "it" is, but I can try to hone in a bit more on the question by describing my immediate, intimate experience when facing the text I am translating, or reading in order to evaluate if I want to translate it. That experience is, quite simply, one of engagement, with the text, the word, and ultimately, the world. And this engagement, on this most basic level, could be deemed "erotic."

I feel the need, here, perhaps due to my famous sense of inadequacy, to acknowledge the long history of the sexualization of translations and translators by some theorists and the critique of that sexualization by others. I hope to offer a slightly 
different perspective on this theme.

First, a few words about the word "engagement." Rather than use the English participial adjective, "engaged," we often turn to the French term. Somehow, the phrase "littérature engagée" has a deeper resonance than "engaged literature" does in English; the French refers to a more conscious tradition. In fact, in order to define "engaged literature" in English, we might need to recur to an internal translation and say "committed literature" or even, more explicitly because this is much less of a given in our, or should I say, the U.S. context, "politically committed literature." To complicate matters even more, we use the word "involved" in English to talk about somebody who is active in politics. The most common translation into Spanish for "engaged" and "politically involved" is "comprometido," or "committed," wherein the "political" is implicit and the involvement is explicit. The place where these meanings overlap in English, curiously enough, is when we are talking about a pre-marital arrangement, where commitment and engagement and involvement become one. Which brings us headlong into "erotic."

For this I turn to John Berger, who wrote a book some thirty-odd years ago called Ways of Seeing. He is still, with each new book he writes, teaching me new ways of seeing. It might seem odd that I bring him up. He's not a translator, nor do I read him in translation. But I do sometimes think that the power and strength of his spare, luminescent prose is related to the fact that he is an Englishman living for four decades in a village in rural France. He lives in a translated world, and I sometimes feel his prose contains its own translation-even if I'm not sure precisely what this meanswhere meaning and means coexist in a dynamic post-translated harmony.

In his 1965 book about Picasso, The Success and Failure of Picasso, he wrote that "part of the force of sex lies in the fact that its subjectivity is mutual" (158). Forty years later, in an essay titled "Another Side of Desire" (129), Berger says that he prefers the adjective "erotic" to "sexual" because it is less reductionist. Let us say, then, following Berger's example and for the purposes of the first part of this discussion, "Erotic, but not necessarily sexual."

Engaging the text, the corporal or incorporated text, and through it, engaging the Other, and the Other world out of which that text emerged and of which it is an integral part. What do we, translators, actually do? We dig into the text; we penetrate its meaning through its means. And moving away from paradigms of domination and submission, which are necessarily gendered, to the best of all possible worlds, we also 
bring the text inside us, arguably to a place before language, and allow it to move from there with the force of its own mystery back out into the light in new and decorative garments. I've often suspected that my initial desire to translate came from the need to clear away the mist, pull aside the veil, denude the text; and the hook that sustains that desire might be that the more we unveil the more we feel the text, literature, language, as coy, a tease that never shows itself in full frontal display. Like Aphrodite, who always keeps a garment on and turns slightly away from the observer.

In that same essay, Berger goes on to talk about desire as a plot hatched by two, a "conspiracy of two" (I don't know about you, but I can hear the French right there under the surface of that phrase, and, right under that, the Latin, "conspirare" to be in harmony with, to breathe together). And it is a conspiracy, I think he is saying, that offers a reprieve from pain, from the wound that is implicit in existence; a conspiracy that creates a place, a locus, of exemption. Viewed from the outside, this exemption is a parenthesis because it is a disappearance, a shift elsewhere, an entry into a plenitude.

A place that exists outside of place or in the place of all places. This is quite different, I think, than being neither here nor there. But it is akin.

We all know, however, that no coupling, no matter how ecstatic, is ever completely harmonious. One and the Other, no matter how close they come, each always remains distinct, in part because this discourse, or intercourse, is alive, thus constantly changing. Where would it take us to consider the relationship, or interaction, between the translation and the original, the translator and the text, dynamic, charged, electric, erotic in the sense of vital and giving of life? And couldn't we see this dynamism, this imperfect harmony, the struggle to become, as lending translation the freedom rather than the onus of placelessness, the privilege of living in the interstice, both temporally and spatially, the elation of engagement and involvement without attachment? In his essay "Of Sadness," Montaigne writes, via his translator, Donald Frame, that: "All passions that allow themselves to be savored and digested are only mediocre" (8-9). The translator's relationship to the text may be many things-intense, obsessive, impassioned - but it is never mediocre.

\section{III}

Which brings us back to love and what the "it" it has to do with is. As a translator, I have been lucky enough to have fallen in love, not just once, but twice in the last few years. It seems significant that both objects of my devotion, both novels, deal to a large extent with the power of language to subvert, both the internal realm of the individual and the world at large. This does not seem so odd: I understand 
subversion as at the core of the translation project itself.

The novel I already mentioned as being partially responsible for propelling me back into translating was My Tender Matador, by the Chilean writer and performance artist, Pedro Lemebel. The story takes place in Santiago, Chile, in 1986, during the darkest days of the Pinochet dictatorship. The main character, much like the author himself, is an aging, lower-class, effeminate homosexual man, a maricón, nameless but referred to as La Loca, literally "the Madwoman," which I translated as the Queen, an interesting displacement of meaning and resonance between the two cultures. Denoted as "she" when self-reflecting and "he" when viewed by others, the Queen falls in love with a young revolutionary, or "terrorist," again depending on your point of view, named Carlos, who asks her to let him store some boxes and meet with his "classmates" in her apartment. She is deliberately kept in the dark about the purpose of their meetings and the "explosive" contents of the boxes, but she is no fool, as she tells herself, and soon puts two and two together. A macho Marxist if ever there was one, Carlos does not reciprocate her feelings of lust and longing, but he learns to appreciate her talent for friendship. One evening, after sharing a bottle of pisco, he tells her the story of a brief homoerotic encounter he had as a boy. Even through her drunken haze, she is disturbed by his tale, not the what but the how:

She wasn't morally offended: she had thousands of stories that were much cruder where blood, semen, and shit had painted the canvas of long nights of lust. No, it wasn't that, she thought, it's the way men tell stories. The brutal way they talk about the urgency of sex, like bullfighters $-\mathrm{Me}$ first, I'll stick it in you, I'll split you in two, I'll put it in, I'll tear you to pieces-with no tact or delicacy. (80)

Carlos's machista discourse contrasts sharply with the Queen's. Hers is a feminized baroque, a deliberate and radical subversion of the rigid strata of gender identification and hierarchy. The positing of such a discourse renders the dominant paradigm relative, rather than absolute; by identifying righteously with the subordinated feminine, the character, and the author, elevates it.

This sounds oddly like the translation project itself: the act of subversion through the insertion of a foreign object into an otherwise complacent, coherent belief system; the offering of an alternative version, a sub-version, from a sub-ordinate world, which irremediably undermines the dominant one in circulation.

The Queen makes her living embroidering tablecloths and other linens, embroidering flowers and birds on the margins; her speech, the language of her 
narrative, is also full of flowers and birds. It is there, on the margins, in that narrow space that poverty, repression, and violence have left for her to inhabit, that she-and Lemebel-manages to create beauty out of ugliness and despair. Thus she decorates her run-down apartment: ". . . the only space the Queen had ever been able to call her own . . . adorning the walls like a wedding cake, populating the cornices with birds, fans, flowering vines, and lace mantillas she draped over the invisible piano" (3).

In one scene, she goes to the home of a General to deliver her lovingly embroidered tablecloth. She knows it will be used on September 11 at the dinner celebrating the anniversary of the coup and begins to imagine its fate: "... red wine splashed on the table, seeped into the cloth, spread out into huge lots where her little birds drowned," and: "Her sentimental sissy eyes watched as they turned her virginal tablecloth embroidered with so much love into a mayhem of murder and drool. Her seamstress sissy eyes saw the off-white linen turned into a violet-colored crime sheet, the drenched shroud of a nation where her angels and birds were drowning" (50).

My most recent translation, Senselessness by Horacio Castellanos Moya, explores, among other things, how syntax, specifically syntactic distortion, can subvert, or pervert, the internal coherence of the individual psyche.

The narrator of this short, breathless novel has been hired by the Catholic Church in an unnamed Central American country to copyedit a report on the massacres of the indigenous communities by the armed forces. As he slogs through the report, he becomes obsessed by snippets of testimonies of the survivors, utterances with the idiosyncratic syntax of traumatized nonnative speakers describing horrific brutality and violence in a way the narrator experiences as poetic. As the book progresses, he becomes more and more paranoid and the syntax of his own narrative begins to get infected by these "poetic" expressions.

Part of the challenge and the joy of translating this text was finding a way to recreate this almost imperceptible process in English. I was also aware that by translating the text into English, introducing it into the cultural and linguistic context of the United States, I was adding yet another layer: the Spanish text, infected by distorted syntax from the native languages, moves into English, thereby infecting English with a distorted syntax from another subordinated language, namely Spanish. The language of the conquered subverts the conquering language through a syntax that undermines the sanity of the narrator, in a text that is then translated into English, the language that has colonized and continues to, as we speak and translate, the original colonizing language 
itself.

In the beginning of the book, the narrator is still holding on to a certain distance between himself and the utterances that so enthrall him, as well as the brutality and violence they convey. These sentences are italicized to emphasize the fact that they have been decontextualized; when the narrator copies them down in his little notebook and obsessively reads them to himself or mostly inappropriately shares them with others, they become further decontextualized. The first of these and the first sentence of the book, repeated over and over in the first few pages, is: "I am not complete in the mind" (17). Here are a sampling of others: "The houses they were sad because no people were inside them" (19); "Because for me the sorrow is to not bury him myself" (20); "While the cadavers they were burning, everyone clapped and they began to eat" (36); "If I die I know not who will bury me" (92). Then, as the end of the book approaches:

"We all know who are the assassins!" (139).

Toward the end of the book, we have lost the italics, and the boundaries. This, now, is the narrator: "As if free of fear I awoke that first morning in my assigned room at the spiritual retreat center ..." (121). And then the next paragraph on the next page begins: "As if free of nightmares I awoke that first morning in that austere room with white walls, lying in my bunk where I enjoyed contemplating, through the glass door that faced the large lawn and the pine forest beyond, the fog drifting by on the breeze" (122).

This particular expression of intersubjectivity is eerily similar to what a translator engages in because it occurs between two minds rather than two bodies, and it occurs through a text, the process implying a most intimate unveiling. Anecdotally, there were moments when the translator's sanity was challenged by the text about a text that was challenging the narrator's sanity. Herein lies a rather brutal example of a common occupational hazard for translators: our minds take on the mind of the writer of the text we are translating. In the jargon of the psychology of human relationships, we translators, like our paranoid and poetically sensitive narrator, sometimes have boundary issues.

\section{IV}

In much the same way that desire fills us with vitality, love elevates us, and meaningful communication, including the occasional and fleeting blurring of boundaries, enthralls, translation almost literally infuses the original with new life by the mere act of engaging it in a dialogue within a new context. This is most apparent 
when considering retranslations of a classic or canonical text. Don Quixote de la Mancha, for instance, the novel though perhaps not the character, is arguably more alive for English speakers than for Spanish speakers since Edith Grossman's new translation reintroduced it into our current literary conversation. This got me thinking with some regret, rather than my more usual complacency or gratitude, about the abundance of great literary texts written in English. Wouldn't it be wonderful if we, too, could have a "new" Trollope, a contemporary Bryon, a fresh George Elliot? How sad that we cannot reintroduce Spenser, even upgrade Henry James. We can, I suppose, always hope for a new BBC miniseries, lest I seem wholly ungrateful. And aren't we lucky Shakespeare wrote plays, which can always be staged anew?

How does this gift of life translation offers play out for a contemporary text, one whose author, for instance, is still alive? That author whom I, as translator, communicate with by email, query regarding her use of a certain term or phrase, or who, I think, drinks too much, is not the writer I engage when I translate her novel. As Margaret Atwood points out in her essay Negotiating with the Dead, the writer is double, one who lives and one who writes. The one who wrote that novel I am now translating existed only at that moment, while she was writing that text, then ceased to exist, having sloughed off the mind I am now, as I translate, taking on. I have often had the sense, when talking to the author whose text I am translating, that I am more engaged with it than she is. Who, then, possesses the text? Can we say that I possess it while I am translating it, but must also, as the author did previously, release it upon my final flourish, when I sign off on those page proofs about to go to the printer? And how, fundamentally, is that ethically distinct from the original writer's relationship to the text, or even, per Atwood, to herself?

Possession and freedom, pivotal issues related to translations and to relationships. We all know that not every dialogue results in understanding, and not every erotic encounter can be passionate or even fun. Only rarely do we fall in love, experience even a partial merger-layering, mutuality-of subjectivities, of desire, a transcendence of the self through our leap into the arms of the Other. Perhaps slightly more often we feel affinity, respect, even admiration, find interest and commonality of mind and material. But the most conflictful encounters, which are often those of the closest kinds, are when we do not wholly respect the autonomy of the Other, when we can tolerate interaction only by trying to change him or her or it. In other words, and to extend the metaphor, edit.

As I mentioned earlier, I also work as an editor (the meaning of this word and 
how poorly it translates into any language would be the subject of another paper). I have become increasingly aware in recent years of the ways editing and translating overlap. Both require deep, concentrated, meticulous, magnifying-glass reading, a kind of reading that exposes failures of execution, narrative inconsistencies, stylistic missteps, and just plain errors. As an editor my job is often to intuit what an author really wanted to say and didn't quite manage to, suggest a more elegant, accurate, or efficient way to do so. As an editor, I mark the page with the pencil or, more often, turn on WORD's track changes feature and decorate the text with colorful and graphic deletions, additions, and comments. As a literary translator, a certain level of such "edits" can, as we all know, be made invisible, obscured under the fog that hovers in that low-lying space between languages. (This brings me back to the idea of a conspiracy of two, writer/translator, and the old ad: "Only her hairdresser knows for sure.") But what does one do when, after unfurling a complex, multilayered, and seemingly elegantly constructed metaphor and parsing it into some form of English, it becomes apparent that it is, god forbid, mixed? How does one deal with a "quiddity," that actually makes no sense, even after extensive etymological, lexicological, and historical research in Google and beyond?

Literature, the literary text as we have known and loved it, is inhabiting an increasingly narrow space, hemmed in on one side by the blockbuster and on the other by the blog. Within this space the role of the editor, and publisher, among the many gatekeepers of culture, is changing, becoming more intrusive on one hand and more neglectful on the other. The implications for the translator-ethically, aesthetically, pragmatically - are far-reaching. One small example: I recently turned in a translation of a novel on which my editors recommended, and initiated, a large-scale developmental edit. Assuming the author's "possession" of the text and my role as guardian of its integrity and "representative" of his ownership, I felt I had a professional responsibility to consult him about every substantive change, every adverb added to a dialogue marker, every paragraph deleted as redundant, every metaphor toned down or dropped because clichéd, convoluted, or simply superfluous. His response surprised me, but in retrospect shouldn't have: he didn't need to see or approve any changes as long as they didn't "change the plot." Without being fully aware of doing so, I had left that space of literature, now in my mind even narrower, and incurred into the (hopeful) arena of the blockbuster. That's a foreign country. They do things differently there.

Maybe Borges's quip, about the original remaining true to the translation, has become a physical, rather than metaphysical concern. 
V

To conclude, I'd like to return to where I left off when I was discussing Senselessness. Back to subversion. Violence. Repression. Back into a world of opposing forces, dichotomies, false or otherwise, and, alas, the objective material conditions.

I'd like to extend the metaphor of engagement from the word - the text-to the world, from the personal to the political, to involvement, compromiso. Because in the real world there is still a class struggle, a gender gap, economic injustice and inequality, and social/cultural/linguistic domination and subordination. And there can be no engagement with any Other, in any relationship of love, eroticism, friendship, or family, through any text whatsoever, that does not contain some kind of "objective" power differential.

How do the specific power differentials between the languages and cultures we translate into and out of, effect translators and the translations we produce? What choices can I make about what I translate and the strategies I use that can most effectively subvert those differentials? What are the specifics of my particular translating "relationship" given my particular "allegiance" or purpose?

I translate mostly Spanish-language Latin American literature into English, and I live in California, where Spanish is spoken by approximately 40 percent of the population, but is not an official second language. A large number of those who speak Spanish in California officially don't exist. They are illegal, though how a human being can be illegal is beyond me. Spanish, for most English speakers in California, is experienced as the language of service or farm workers, the poorly educated, the silent and the invisible, the outsiders, the Others. Probably the best-selling "translations" are those little phrasebooks, "How to Talk to Your Housekeeper" "How to Talk to Your Gardener" in other words "How to Give Instructions" to any number of workers who do what one doesn't want to or have the time to do oneself. In my children's elementary school, 30 percent of the families were Spanish-speaking, many of them recent immigrants, but it took me three years to find a native Spanish speaker willing and able to relieve me of the task of translating school communications into Spanish, and the onus of desecrating the Spanish language while I did so. Most teachers of Spanish I've encountered in the public school are not native speakers. Mind-boggling when you think of it.

In this case, the receiving culture-Anglophone North America-is not a blank slate as far as familiarity with the source language and culture; rather, it abounds in 
prejudices, misconceptions, distorted imaginings, based on its experience with a particular class from within that culture. The "foreign" is all-too-familiar, known but understood in one dimension. Subversion, in this context, comes from both directions, from above, and from below. The United States has been directly subverting the economic, political, and cultural landscape of the Spanish-speaking world in the Americas for more than a century. Within that context, and without diminishing the importance of what and how we translate, I would posit that the very act of translating literature from Latin America is an act of resistance, a complement to the slow, patient, yet inexorable resistance that world is offering, through numbers, through movement north, through the proverbial sweat of the brow, through noticing when the monster is otherwise distracted and moving away from possession, toward freedom.

On a textual level, this becomes relevant for a translator working with contemporary literature from the Americas when, for instance, she confronts Spanglish and Engnish. Because, ojo! beware, as they say in Spanish. The power differentials, this process of infection or interpenetration, is not by any means of equal valence; the exchange is not interchangeable. Though I don't have time to explore this in more detail, I again recur to the objective material conditions, one in particular, to leave no room for doubt: capital is free to move at will; labor, a.k.a. human beings, are not.

More or less a couple of thousands of years ago, an anonymous person or group of people wrote in a book called "Ecclesiastics" the assertion that "Ayn hadash tachat hashemesh," or, "There's nothing new under the sun." If this could be asserted, perhaps wistfully, then, how much more forcefully now, after all this accumulated verbiage. I've adopted this sentence as my mantra, just to make sure I don't forget, not only about the plurality of meaning but about the relative way we assign value and purpose. It settles me into this place of translation, connected so profoundly to the larger human conversation across time and place, and helps me remember, despite the unpaid bills, that I love it for what it is and for what it is not. 
http://ejournals.library.ualberta.ca/index.php/TC

\section{REFERENCES}

Atwood, Margaret. Negotiating With the Dead: A Writer on Writing. Cambridge: Cambridge UP, 1992.

Berger, John. "The Other Side of Desire." Hold Everything Dear. New York: Pantheon Books, 2007.

---. The Success and Failure of Picasso. New York: Pantheon Books, 1965.

---. Ways of Seeing. New York: Penguin Books, 1972.

Castellanos Moya, Horacio. Senselessness. New York: New Direction Publishing, 2008.

Lemebel, Pedro. My Tender Matador. Trans. Katherine Silver. New York: Grove Press, 2003.

Montaigne, Michel de. The Complete Works. Trans. Donald Frame. New York: Alfred A. Knopf, 2003. 